\title{
Alterações morfométricas em grãos de soja durante o processo de secagem
}

\section{Morphometric alterations in soy bean during drying process}

\author{
Daniel Emanuel Cabral de Oliveira ${ }^{1 *}$; Osvaldo Resende ${ }^{2}$; Thaís Adriana de Souza \\ Smaniotto $^{3}$; Valdiney Cambuy Siqueira ${ }^{4}$; Colemar Antônio José Neto ${ }^{5}$
}

\section{Resumo}

O trabalho teve por objetivo avaliar as curvas de secagem, bem como os efeitos da secagem em diferentes temperaturas na contração volumétrica da massa de grãos e no diâmetro geométrico da soja M7211RR. Foram utilizados grãos de soja da cultivar M7211RR colhidos no município de Santa Helena de Goiás-GO, com teor de água inicial de aproximadamente 0,30 base seca (b.s. decimal) e secos até atingir 0,13 (b.s.). O experimento foi conduzido no Laboratório de Pós-Colheita de Produtos Vegetais do Instituto Federal Goiano - Câmpus Rio Verde. Durante o processo de secagem, os eixos ortogonais (comprimento, largura e espessura) dos grãos de soja foram medidos para determinação do diâmetro geométrico. Para a obtenção da contração volumétrica, os grãos foram secos em bandejas e posteriormente colocados em proveta graduada e assim a redução do volume do produto foi acompanhada ao longo da secagem. $\mathrm{O}$ aumento da temperatura de $50^{\circ} \mathrm{C}$ para $90^{\circ} \mathrm{C}$ diminui o tempo de secagem de 7,66 horas para 1,98 horas, promovendo a celeridade do processo em 3,87 vezes. $\mathrm{O}$ índice de contração volumétrica e o diâmetro geométrico da soja diminuem ao longo da secagem e este efeito é intensificado com o aumento da temperatura.

Palavras-chave: Propriedades físicas, teor de água, diâmetro geométrico

\begin{abstract}
The study aimed to evaluate the drying curves and the effects of drying temperature on the volumetric shrinkage of the grain mass and geometric diameter of the soy bean M7211RR. Were used soy bean the cultivar M7211RR harvested in Santa Helena de Goiás-GO, with an initial moisture content of approximately 0.30 d.b. (decimal dry basis) and dried to 0.13 (d.b.). The experiment was conducted at Laboratório de Pós-Colheita de Produtos Vegetais of the Instituto Federal Goiano - Câmpus Rio Verde. During the drying process, the orthogonal axes (length, width and thickness) of soy beans were measured to determine the geometric diameter. To obtain the volumetric shrinkage, the soy bean was dried on trays and then placed in graduated cylinder and thus reducing the volume of product was monitored throughout the drying. Increasing the temperature of $50{ }^{\circ} \mathrm{C}$ to $90{ }^{\circ} \mathrm{C}$ decreases the drying time of 7.66 hours to 1.98 hours, streamlining the process for 3.87 times. The rate of shrinkage and the diameter geometric of soybean decreases during drying, and this effect is intensified with increasing temperature.
\end{abstract}

Key words: Physical properties, moisture content, geometric diameter

1 Eng ${ }^{\text {O }}$ Agrícola, Prof. M.e. da Universidade Federal do Mato Grosso, Sinop, MT. E-mail: oliveira.d.e.c@gmail.com

2 Eng ${ }^{\text {O }}$ Agrícola, Prof. Dr. do Instituto Federal de Educação, Ciência e Tecnologia Goiano, Rio Verde, GO. E-mail: osvresende@ yahoo.com.br

3 Discente de Doutorado em Ciências Agrárias - Agronomia, Instituto Federal de Educação, Ciência e Tecnologia Goiano, Rio Verde, GO. E-mail: tatiadris@ig.com.br

4 Discente de Doutorado em Engenharia Agrícola, Universidade Federal de Lavras, UFLA, Lavras, MG. E-mail: vcambuy@ yahoo.com

5 Discente de Mestrado em Ciências Agrárias - Agronomia, Instituto Federal de Educação, Ciência e Tecnologia Goiano, Rio Verde, GO. E-mail: colemarneto@hotmail.com

Autor para correspondência 


\section{Introdução}

A soja (Glycine $\max$ (L.) MERRILL) é uma planta de origem asiática e a sua produção tem grande expressão na economia brasileira. São diversos fatores que contribuem para a valorização deste produto e seus subprodutos, como o alto teor de óleo e proteína (RIBEIRO et al., 2005).

As propriedades físicas dos produtos agrícolas têm seu uso irrestrito, podendo ser utilizado em estudos de aerodinâmica, na otimização dos processos industriais, projeto e dimensionamento de equipamentos empregados nas operações de colheita e pós-colheita (RESENDE et. al., 2005). Corrêa et al. (2002) ressaltam que o conhecimento das características físicas em produtos granulares tem grande importância em estudos de transferência de calor e massa e movimentação de ar.

O processo de secagem proporciona a perda de água causando danos nas estruturas celulares do produto, com isto leva à mudanças na forma e decréscimo em suas dimensões (MAYOR; SERENO, 2004). Para Prado, Alonso e Park (2000), a contração volumétrica é promovida pela redução da tensão existente no interior das células devido a remoção da água durante a secagem.

Lozano, Rotstein e Urbicain (1983), Bala e Woods (1984), Towner (1987), Ratti (1994), Sokhansanj e Lang (1996), relatam que as mudanças volumétricas são a principal causa das alterações das propriedades físicas dos produtos agrícolas.

A contração volumétrica dos produtos vegetais durante a secagem não está ligada somente ao teor de água, depende das condições de secagem, forma e tamanho do produto (RATTI, 1994; ZOGZAS; MAROULIS; KOURIS, 1994), e envolvem leis complexas de mecânicas e de deformação de materiais (TOWNER, 1987). Para Siqueira, Resende e Chaves (2012), o estudo da contração volumétrica durante o processo de secagem permite predizer o volume ocupado pela massa de grãos, conforme ocorre a redução do teor de água, sendo desta forma de fundamental importância para o desenvolvimento de novos equipamentos de secagem.
O diâmetro geométrico e a contração volumétrica durante o processo de secagem tem sido o objeto de estudo de diversos pesquisadores (KOÇ; EREN; ERTEKIN, 2008; MAYOR; SERENO, 2004; RAZAVI et. al., 2007; RESENDE et. al., 2005; RIBEIRO et. al., 2005; CORRÊA et. al., 2011).

Goneli et al. (2011) estudaram frutos de mamona e certificaram que a contração volumétrica durante a secagem proporciona a redução de todas as dimensões do fruto, inclusive para o diâmetro geométrico médio. Siqueira, Resende e Chaves (2011), verificaram que o decréscimo do diâmetro geométrico é proporcional a redução do teor de água, independentemente da condição de secagem.

Diante o exposto, o objetivo no presente trabalho foi avaliar as curvas de secagem, bem como os efeitos da secagem em diferentes temperaturas na contração volumétrica da massa de grãos e no diâmetro geométrico da soja M7211RR.

\section{Material e Métodos}

O trabalho foi desenvolvido no Laboratório de Pós-Colheita de Produtos Vegetais, no Instituto Federal Goiano - Câmpus Rio Verde. No experimento foram utilizados grãos de soja da cultivar M-7211 RR, proveniente do município de Santa Helena de Goiás, GO.

Inicialmente foi realizada uma seleção dos grãos e a preparação das amostras, sendo estas submetidas à secagem em estufa com ventilação forçada nas temperaturas do ar de $50{ }^{\circ} \mathrm{C} \mathrm{e} 90^{\circ} \mathrm{C}$. O teor de água inicial dos grãos foi de aproximadamente 0,30 (b.s.).

A redução do teor de água, ao longo da secagem, foi acompanhada pelo método gravimétrico (perda de massa), sendo realizadas pesagens em balanças analíticas com resolução de 0,001 gramas, até os grãos atingirem o teor de água de $0,13 \pm 0,004$ (b.s.). Para determinar os teores de água foi utilizado o método da estufa a $105 \pm 3{ }^{\circ} \mathrm{C}$ durante 24 horas, com três repetições (BRASIL, 2009). 
Para a contração volumétrica da massa, a secagem dos grãos foi realizada em bandejas metálicas e a redução do volume, durante a secagem, foi determinada utilizando uma proveta de $250 \mathrm{~mL}$, com três repetições.

$\mathrm{O}$ índice de contração volumétrica foi determinado pela relação entre o volume encontrado em cada teor de água e o volume inicial (RESENDE et. al., 2005).

$$
\Psi=\frac{\mathrm{V}}{\mathrm{V}_{\mathrm{i}}}
$$

em que:

$\Psi=$ Índice de contração volumétrica, decimal;

$\mathrm{V}=$ volume em cada teor de água, $\mathrm{m}^{3}$;

$\mathrm{V}_{\mathrm{i}}=$ volume inicial, $\mathrm{m}^{3}$.

Para determinar o diâmetro geométrico, foram utilizados 15 grãos de soja conforme metodologia adaptada de Siqueira, Resende e Chaves (2011), individualizados em cápsulas de alumínio, com dimensões de 60,12 mm de diâmetro e 41,0 mm de altura, e a cada teor de água estimado foram medidos os eixos ortogonais dos grãos (Figura 1), com o auxílio de um paquímetro digital com resolução de $0,01 \mathrm{~mm}$.

Figura 1. Desenho esquemático do grão de soja com suas dimensões ortogonais.

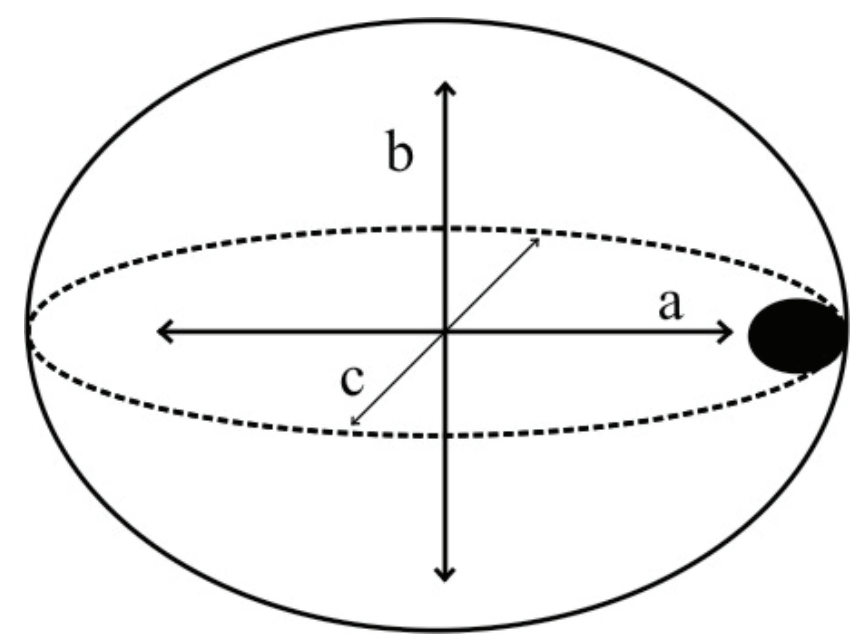

Fonte: Elaboração dos autores.

Em que a é o comprimento ou maior eixo ( $\mathrm{mm})$, b é a largura ou eixo médio ( $\mathrm{mm}$ ) e o c é a espessura ou menor eixo (mm).

A redução do teor de água foi acompanhada por meio da pesagem de três bandejas com a massa inicial de $170 \mathrm{~g}$ de produto perfazendo uma camada de $10 \mathrm{~mm}$ de grãos, sendo mantidas nas mesmas condições de secagem, às quais os 15 grãos foram submetidos. Com isto, o diâmetro geométrico foi determinado pela equação (2) proposta por Mohsenin (1986):

$$
\operatorname{Dg}=(a \cdot b \cdot c)^{\frac{1}{3}}
$$

em que:

a: comprimento ou maior eixo, $\mathrm{mm}$;

b: largura ou eixo médio, $\mathrm{mm}$;

c: espessura ou menor eixo, $\mathrm{mm}$. 
O experimento foi montado em esquema fatorial, tendo como fatores as diferentes temperaturas (50 e $90{ }^{\circ} \mathrm{C}$ ) e os teores de água ao longo da secagem $(0,31 ; 0,27 ; 0,24 ; 0,21 ; 0,18 ; 0,16$ e 0,13 b.s. $)$, em delineamento inteiramente casualizado. Os dados foram analisados por meio de análise de variância e regressão, sendo os modelos selecionados de acordo com o coeficiente de determinação $\left(\mathrm{R}^{2}\right)$ e pela significância da equação pelo teste $\mathrm{F}$, com o auxílio do programa aplicativo SISVAR 5.3, de acordo com Ferreira (2008). Aliado a essas análises estatísticas, empregou-se o teste do erro médio relativo $(\mathrm{P})$ para validar o modelo empregado. O erro médio relativo foi calculado conforme a seguinte expressão:

$$
P=\frac{100}{N} \sum \frac{|Y-\hat{Y}|}{Y}
$$

em que:

Y : valor experimental;

$\hat{\mathrm{Y}}$ : valor estimado pelo modelo; e

$\mathrm{N}$ : número de observações experimentais;

\section{Resultados e Discussão}

$\mathrm{Na}$ Tabela 1 estão apresentadas as análises estatísticas da contração volumétrica e diâmetro geométrico, ambas submetidas à secagem na temperatura de 50 e $90^{\circ} \mathrm{C}$. Verifica-se que a interação entre os dois fatores, teor de água e temperatura, não foi significativa para as duas variáveis estudadas. Entretanto, o efeito do teor de água foi significativo demonstrando que a contração volumétrica e o diâmetro geométrico foram influenciados pelo teor de água. Já o efeito da temperatura foi verificado apenas no diâmetro geométrico.

Tabela 1. Resumo da análise de variância para a contração volumétrica e o diâmetro geométrico dos grãos de soja submetidos a diferentes temperaturas de secagem.

\begin{tabular}{ccc}
\hline Fonte de Variação & \multicolumn{2}{c}{ Quadrados médios } \\
\hline & Contração Volumétrica & Diâmetro Geométrico \\
\cline { 2 - 3 } Teor de Água & $0,019278^{* *}$ & $0,180577^{* *}$ \\
Temperatura & $0,000075^{\mathrm{NS}}$ & $2,257629^{* *}$ \\
Teor de Água x Temperatura & $0,000151^{\mathrm{NS}}$ & $0,014987^{\mathrm{NS}}$ \\
\hline Coeficiente de variação $(\mathrm{CV})$ & 1,72 & 3,07 \\
\hline
\end{tabular}

**Significativa a $1 \%$ de significância, pelo teste $\mathrm{F}$.

*Significativa a 5\% de significância, pelo teste F.

NSNão significativa.

Fonte: Elaboração dos autores.

Nota-se que o coeficiente de variação $(\mathrm{CV})$ da contração volumétrica e do diâmetro geométrico foram baixos, 1,72 e 3,07, respectivamente. Mostrando que houve pouca variação nos resultados experimentais.

$\mathrm{Na}$ Figura 2 estão apresentadas as curvas de secagem para os grãos de soja submetidos à secagem a 50 e $90{ }^{\circ} \mathrm{C}$. Nota-se que para reduzir de aproximadamente 0,31 (decimal b.s.) a 0,13 (decimal b.s.) foram necessárias 7,66 horas durante a secagem na temperatura de $50{ }^{\circ} \mathrm{C}$. Já para a temperatura de $90{ }^{\circ} \mathrm{C}$ foram necessárias 1,98 horas de secagem. O tempo de secagem a $90{ }^{\circ} \mathrm{C}$ foi 3,87 vezes mais rápido. De acordo com Siqueira, Resende e Chaves (2013), temperaturas mais altas promovem uma maior taxa de secagem, decorrente da maior diferença entre a pressão de vapor d'água do ar de secagem e do produto, e isso faz com que a água seja removida com mais facilidade e rapidez. 
Corroborando os dados obtidos, Leite et al. menor tempo. Afonso Júnior e Corrêa (2000a), (2005), estudando a secagem de milho comum em diferentes temperaturas e fluxo de ar, verificaram que o tempo total de secagem diminuiu com o aumento da temperatura para o mesmo fluxo e com o aumento do fluxo para a mesma temperatura diminuiu o tempo de secagem.

Na Figura 3, verifica-se o índice de contração dos grãos de soja para as duas temperaturas, em função do tempo de secagem. Verifica-se que na temperatura mais elevada o produto contraiu em estudando a cinética de contração de milho pipoca das cultivares CMS 43 e Zélia em diferentes temperaturas, verificaram que o aumento da temperatura do ar de secagem, em ambas cultivares, promoveu a contração volumétrica do produto em um menor período de tempo.

O modelo polinomial de segundo grau obteve o melhor ajuste, com o coeficiente de determinação de $98,05 \%$ e $96,33 \%$ para as temperaturas de 50 e $90{ }^{\circ} \mathrm{C}$, respectivamente (Tabela 2 ).

Figura 2. Teor de água dos grãos de soja em função do tempo de secagem para as temperaturas de 50 e $90{ }^{\circ} \mathrm{C}$.

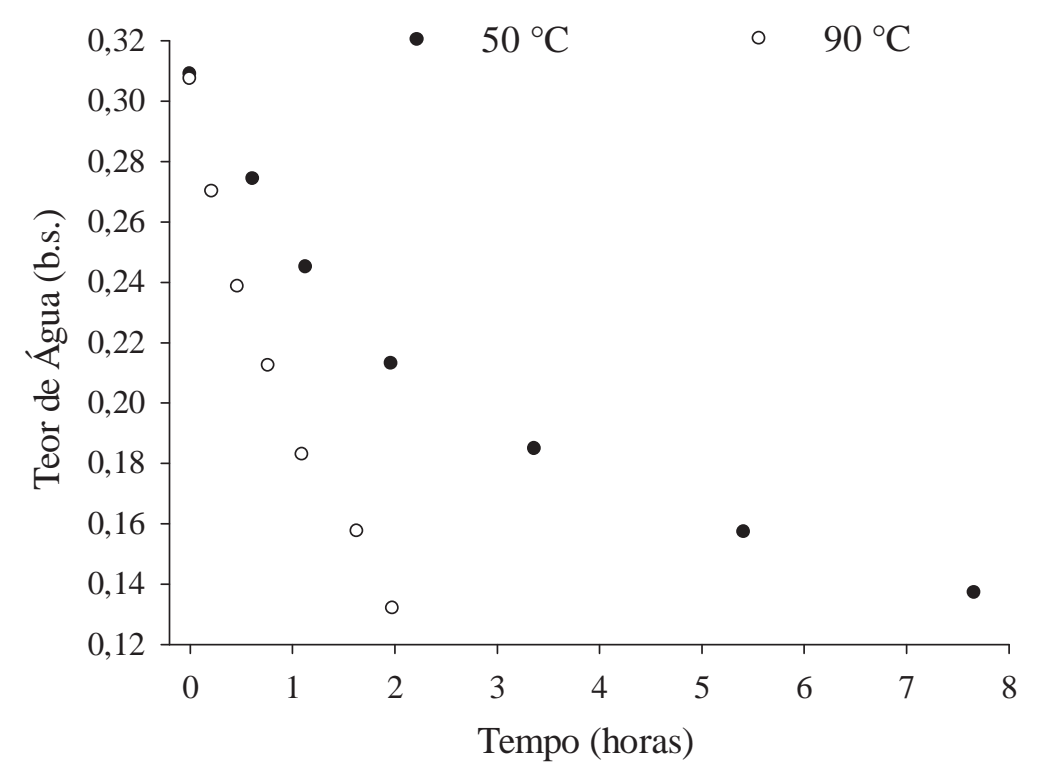

Fonte: Elaboração dos autores. 
Figura 3. Índice de contração volumétrica em relação ao tempo de secagem para as temperaturas de 50 e $90^{\circ} \mathrm{C}$.

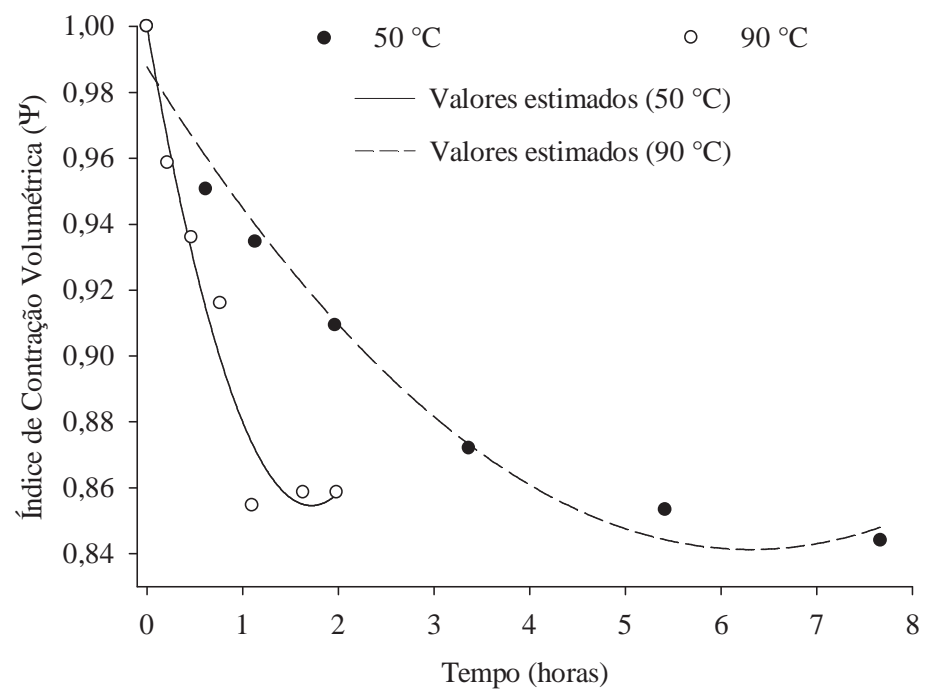

Fonte: Elaboração dos autores.

Durante a secagem a $90{ }^{\circ} \mathrm{C}$ verificou-se a temperatura de secagem em sementes de feijão, presença de trincas e a separação dos cotilédones em alguns grãos. Este comportamento pode ter aumentado a remoção de água do produto. Weller, verificaram que incremento da temperatura do ar de secagem aumenta a suscetibilidade a quebra das sementes.

Paulsen e Steinberg (1990) e Alves et al. (2001), verificaram que com o aumento do teor de água na colheita e da temperatura na secagem tem-se acréscimo no índice de trincas. Afonso Júnior e Corrêa (2000b), estudando o efeito do aumento da

$\mathrm{Na}$ Figura 4 está apresentada a contração volumétrica dos grãos de soja em função do teor de água. Nota-se o mesmo comportamento para as diferentes temperaturas de secagem, sendo que o índice de contração diminuiu ao longo da secagem.

Figura 4. Índice de contração volumétrica dos grãos de soja durante a secagem nas temperaturas de 50 e $90{ }^{\circ} \mathrm{C}$.

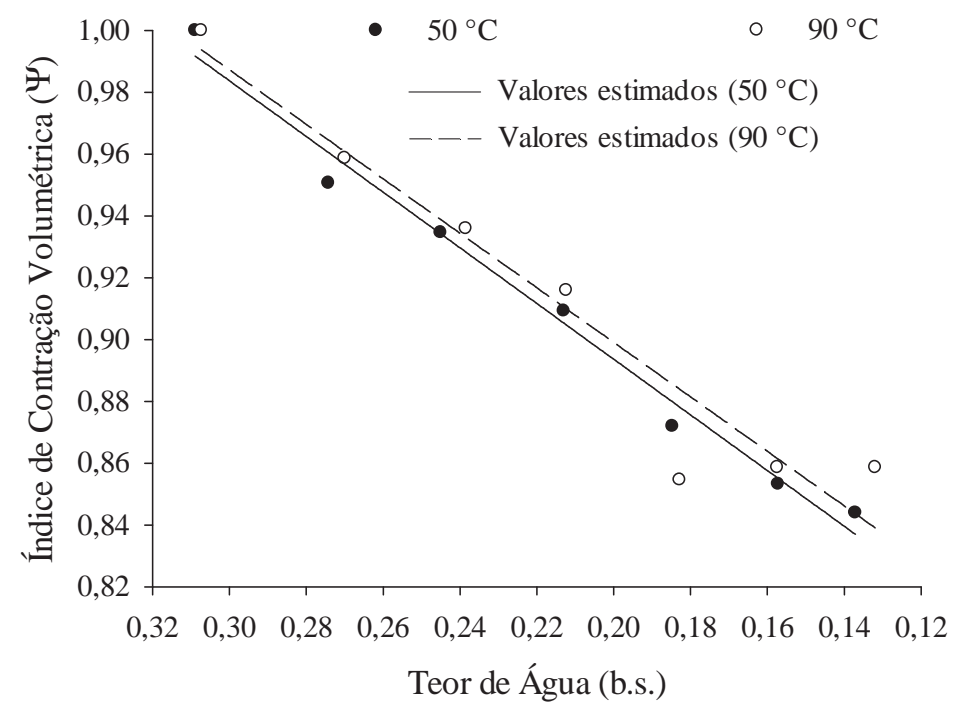

Fonte: Elaboração dos autores. 
De maneira semelhante ao presente trabalho, Afonso Junior e Corrêa (2000a) e Resende et al. (2005), trabalhando com milho pipoca e feijão respectivamente, observaram que o modelo linear representou adequadamente o índice de contração quando relacionado com o de teor de água.

$\mathrm{Na}$ Figura 5 estão apresentados os valores do diâmetro geométrico dos grãos de soja ao longo da secagem. Observa-se que o diâmetro geométrico, diminuiu ao longo da secagem para ambas as temperaturas. Na temperatura de $50{ }^{\circ} \mathrm{C}$ essa redução representou 2,69 pontos percentuais do diâmetro geométrico inicial, enquanto que para a temperatura de $90{ }^{\circ} \mathrm{C}$ essa redução foi de 3,8 pontos percentuais.

Goneli et al. (2011), verificaram que o diâmetro geométrico dos grãos de mamona diminuíram ao longo da secagem. Siqueira, Resende e Chaves (2012), trabalhando com grãos de pinhão-manso com diferentes teores de água e temperaturas, observaram que não houve diferença estatística para o diâmetro geométrico. No mesmo estudo, verificaram que o diâmetro geométrico dos grãos diminuiu para baixos teores de água, independentemente da condição de secagem analisada.

Figura 5. Diâmetro Geométrico dos grãos de soja $(\mathrm{Dg})$ em relação ao teor de água para as temperaturas de 50 e $90{ }^{\circ} \mathrm{C}$.

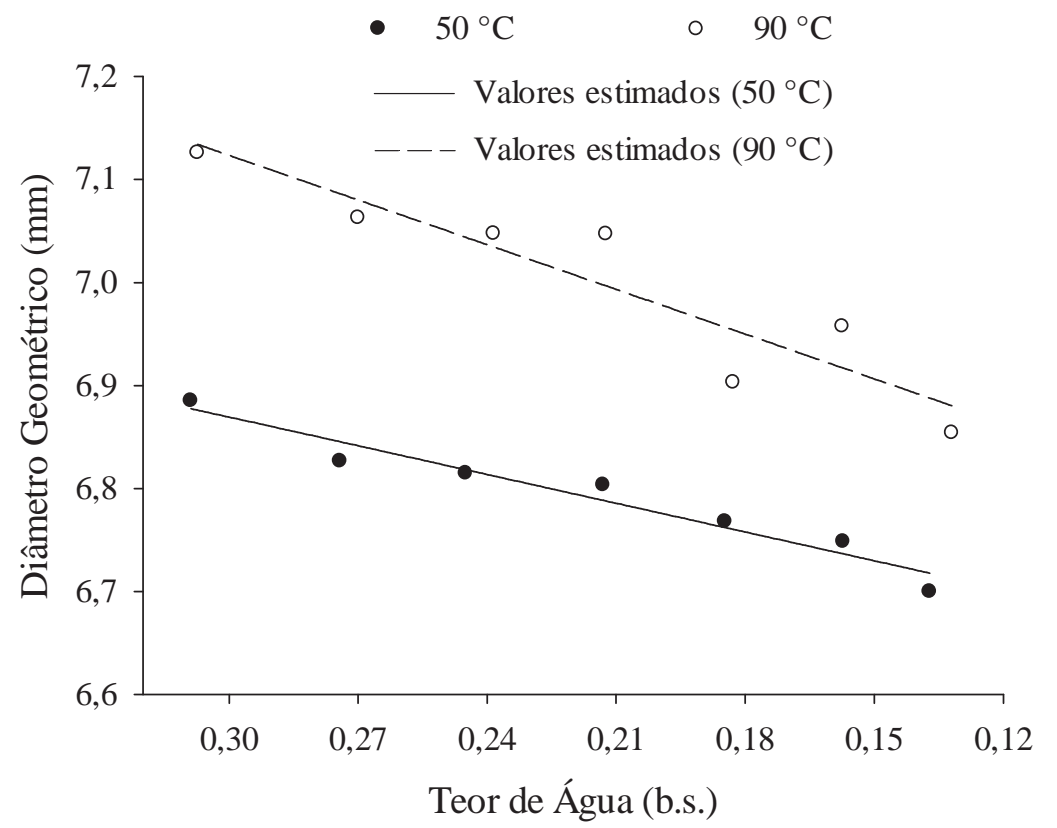

Fonte: Elaboração dos autores.

O modelo linear representou, adequadamente, os dados do diâmetro geométrico e do índice de contração volumétrica em relação ao teor de água, para as duas temperaturas. Entretanto, para a temperatura de $50{ }^{\circ} \mathrm{C}$ não houve diferença significativa. Razavi et al. (2007) e Siqueira, Resende e Chaves (2011), estudando pistachio e frutos de pinhão-manso, respectivamente, verificaram que o modelo linear representou adequadamente o comportamento do diâmetro geométrico durante a secagem, independente da condição de secagem.

$\mathrm{Na}$ Tabela 2 estão apresentados os modelos ajustados para a contração volumétrica em função do tempo e do teor de água, além do diâmetro geométrico para a secagem em duas condições de temperatura. Nota-se que os modelos obtiveram alto nível de significância para o coeficiente de 
determinação $\left(\mathrm{R}^{2}\right)$; sendo que apenas o diâmetro geométrico a $90{ }^{\circ} \mathrm{C}$ não foi significativo de acordo com o teste de F. Todos os modelos analisados, apresentaram um baixo erro médio relativo $(\mathrm{P})$, sendo inferiores a $10 \%$, que segundo Mohapatra e Rao (2005), indicam que os modelos representam adequadamente o efeito do teor de água e do tempo de secagem na contração volumétrica e no diâmetro geométrico dos grãos.

Tabela 2. Equações ajustadas aos valores da contração volumétrica em função do teor de água (Ta, decimal b.s.) e do tempo de secagem (t, horas), bem como do diâmetro geométrico dos grãos de soja para as temperaturas de 50 e $90{ }^{\circ} \mathrm{C}$.

\begin{tabular}{|c|c|c|c|}
\hline & \multicolumn{3}{|l|}{$50^{\circ} \mathrm{C}$} \\
\hline & Equação & $\mathrm{R}^{2}$ & $\mathrm{P}(\%)$ \\
\hline Contração Volumétrica / Teor de Água & $\Psi=0,9005 \mathrm{Ta}+0,7136$ & $98,48^{* *}$ & 0,61 \\
\hline Contração Volumétrica / Tempo & $\Psi=0,0037 \mathrm{t}^{2}-0,0464 \mathrm{t}+0,9877$ & $98,05 * *$ & 0,66 \\
\hline \multirow[t]{3}{*}{ Diâmetro Geométrico } & $\mathrm{Dg}=0,9297 \mathrm{Ta}+6,5904$ & $94,86^{*}$ & 0,17 \\
\hline & \multicolumn{3}{|l|}{$90^{\circ} \mathrm{C}$} \\
\hline & Equação & $\mathrm{R}^{2}$ & $\mathrm{P}(\%)$ \\
\hline Contração Volumétrica / Teor de Água & $\Psi=0,8816 \mathrm{Ta}+0,7229$ & $93,14 * *$ & 1,12 \\
\hline Contração Volumétrica / Tempo & $\Psi=0,0492 \mathrm{t}^{2}-0,1690 \mathrm{t}+0,9998$ & $96,33 * *$ & 0,82 \\
\hline Diâmetro Geométrico & $\mathrm{Dg}=1,4453 \mathrm{Ta}+6,6899$ & $85,96^{\mathrm{NS}}$ & 0,42 \\
\hline
\end{tabular}

**Significativa a $1 \%$ de significância, pelo teste F.

* Significativa a 5\% de significância, pelo teste F.

NSNão significativa.

Fonte: Elaboração dos autores.

Os ajustes dos modelos linear e quadrático para contração volumétrica e diâmetro geométrico vêm sendo utilizado por diversos pesquisadores como Afonso Júnior e Corrêa (2000a), Afonso Júnior et al. (2003), Resende et al. (2005), Ribeiro et al. (2005) e Goneli et al. (2011).

\section{Conclusões}

O aumento da temperatura de $50{ }^{\circ} \mathrm{C}$ para $90{ }^{\circ} \mathrm{C}$ diminui o tempo de secagem de 7,66 horas para 1,98 horas, promovendo a celeridade do processo em 3,87 vezes.

O índice de contração volumétrica e o diâmetro geométrico da soja diminuem ao longo da secagem e este efeito é intensificado com o aumento da temperatura.

\section{Referências}

AFONSO JÚNIOR, P. C.; CORRÊA, P. C.; PINTO, F. A. C.; SAMPAIO, C. P. Shrinkage evaluation of five different varieties of coffee berries during the drying process. Biosystems Engineering, Londres, v. 86, n. 4, p. 481-485, 2003.

AFONSO JÚNIOR, P. C.; CORRÊA, P. C. Cinética da contração volumétrica dos grãos de duas cultivares de milho-pipoca durante o processo de secagem. Revista Brasileira de Produtos Agroindustriais, Campina Grande, v. 2, n. 1, p. 61-65, 2000a.

- Efeitos imediato e latente da secagem de sementes de feijão colhidas com diferentes níveis de umidade. Ciência e Agrotecnologia, Lavras, v. 24, p. 3340, 2000b. Edição especial.

ALVES, W. M.; FARONI, L. R. A.; QUEIROZ, D. M.; CORRÊA, P. C.; GALVÃO, J. C. C. Qualidade dos grãos de milho em função da umidade de colheita e da temperatura de secagem. Revista Brasileira de Engenharia Agrícola e Ambiental, Campina Grande, v. 5, n. 3, p. 469-474, 2001.

BALA, B. K.; WOODS, J. L. Simulation of deep bed malt drying. Journal Agricultural Engineering Research, New York, v. 30, n. 3, p. 235-244, 1984. 
BRASIL. Ministério da Agricultura, Pecuária e Abastecimento. Secretaria de Defesa Agropecuária. Regra para análise de sementes. Brasília: Mapa/ACS, 2009. 399 p.

CORRÊA, P. C.; AFONSO JÚNIOR, P. C.; QUEIROZ, D. M.; SAMPAIO, C. P.; CARDOSO, J. B. Variação das dimensões características e da forma dos frutos de café durante o processo de secagem. Revista Brasileira de Engenharia Agrícola e Ambiental, Campina Grande, v. 6, n. 3, p. 466-470, 2002.

CORRÊA, P. C.; RESENDE, O.; GARIN, S. A.; JAREN, C.; OLIVEIRA, G. H. H. Mathematical models to describe the volumetric shrinkage rate of red beans during drying. Revista Engenharia Agrícola, Jaboticabal, v. 31, n. 4, p. 716-726, 2011.

FERREIRA, D. F. SISVAR: um programa para análises estatísticas e ensino de estatística. Revista Symposium, Lavras, v. 6, n. 2, p. 36-41, 2008.

GONELI, A. L. D.; CORRÊA, P. C.; MAGALHÃES, F. E. A.; BAPTESTINI, F. M. Contração volumétrica e forma dos frutos de mamona durante a secagem. Acta Scientiarum. Agronomy, Maringá, v. 33, n. 1, p. 1-8, 2011.

KOÇ, B.; EREN, I.; ERTEKIN, F. K. Modelling bulk density, porosity and shrinkage of quince during drying: The effect of drying method. Journal of Food Engineering, Londres, v. 85, n. 3, p. 340-349, 2008.

LEITE, J. C. A.; SOUSA, R. F.; SILVA, A. S.; GOUVEIA, J. P. G.; SILVA, M. M.; SOUSA, A. G. Simulação de secagem de milho (Zea mays L.) utilizando modelo matemático de Thompson. Revista de Biologia e Ciências da Terra, Campina Grande, v. 5, n. 2, p. 14-25, 2005.

LOZANO, J. E.; ROTSTEIN, E.; URBICAIN, M. J. Shrink-age, porosity and bulk density of foodstuffs at changing moisture content. Journal of Food Science, Chicago, v. 48, n. 5, p. 1497-1502, 1983.

MAYOR, L.; SERENO, A. M. Modelling shrinkage during convective drying of food materials: a review. Journal of Food Engineering, Londres, v. 61, n. 3, p. 373-386, 2004.

MOHAPATRA, D.; RAO, P. S. A thin layer drying model of parboiled wheat. Journal of Food Engineering, Londres, v. 66, n. 4, p. 513-518, 2005.

MOHSENIN, N. N. Physical properties of plant and animal materials. New York: Gordon and Breach Publishers, 1986.
PRADO, M. E. T.; ALONSO, L. F. T.; PARK, K. J. Shrinkage of dates (Phoenix Dacyilyfera L.) during drying. Drying Technology, New York, v. 18, n. 1-2, p. 295-310, 2000.

RATTI, C. Shrinkage during drying of foodstuffs. Journal of Food Engineering, Londres, v. 23, n. 1, p. 91105, 1994.

RAZAVI, S. M. A.; RAFE, A.; MOGHADDAM, M. T.; AMINI, A. M. The physical properties of pistachio nut and kernel as a function of moisture content and variety: part II. Gravimetrical properties. Journal of Food Engineering, Londres, v. 81, n. 1, p. 218-225, 2007.

RESENDE, O.; CORREAA, P. C.; GONELI, A. L. D.; CECON, P. R. Forma, tamanho e contração volumétrica do feijão (Phaseolus vulgaris L.) durante a secagem. Revista Brasileira de Produtos Agroindustriais, Campina Grande, v. 7, n. 1, p. 15-24, 2005.

RIBEIRO, D. M.; CORRÊA, P. C.; RODRIGUES, D. H.; GONELI, A. L. D. Análise da variação das propriedades físicas dos grãos de soja durante o processo de secagem. Ciência e Tecnologia de Alimentos, Campinas, v. 25, n. 3, p. 611-617, 2005.

SIQUEIRA, V. C.; RESENDE, O.; CHAVES, T. H. Contração volumétrica dos frutos de pinhão-manso durante a secagem em diversas temperaturas. Revista Brasileira de Armazenamento, Viçosa, v. 36, n. 2, p. 171178, 2011.

Determination of the volumetric shrinkage in jatropha seeds during drying. Acta Scientiarum. Agronomy, Maringá, v. 34, n. 3, p. 231-238, 2012.

Mathematical modelling of the drying of jatropha fruit: an empirical comparison. Revista Ciência Agronômica, Fortaleza, v. 44, n. 2, p. 278-285, 2013.

SOKHANSANJ, S.; LANG, W. Prediction of kernel and bulk volume of wheat and canola during adsorpsion and desorption. Journal of Agricultural Engineering Research, New York, v. 63, n. 2, p. 129-136, 1996.

TOWNER, G. D. The tensile stress generated in clay through drying. Journal of Agricultural Engineering Research, New York, v. 37, n. 3-4, p. 279-289, 1987.

WELLER, C. L.; PAULSEN, M. R.; STEINBERG, M. P. Stress cracking and breakage susceptibility as affected by moisture content at harvest for four yellow dent corn hybrids. Transactions of the ASAE, St. Joseph, v. 33, n. 3, p. 863-869, 1990.

ZOGZAS, N. P.; MAROULIS, Z. B.; KOURIS, D. M. Densities, shrinkage and porosity of some vegetables during air drying. Drying Technology, New York, v. 12, n. 7, p. 1653-1666, 1994. 
